\title{
BODY MASS INDEX OF ELDERLY EUROPEANS
}

\author{
Ene-Margit Titit ${ }^{1}$, Kai SAKs ${ }^{2}$ \\ ${ }^{1}$ Faculty of Mathematics and Computer Science, \\ University of Tartu, Tartu, Estonia \\ ${ }^{2}$ Faculty of Medicine, University of Tartu, Tartu, Estonia
}

\begin{abstract}
SHARE data about older (aged 50 and more) Europeans are used to assess the adequacy of the traditional scale for deciding if a person is underweight, normal, overweight or obese. The results of measurements and calculations in 17 countries (15 from the EU, including Estonia, plus Switzerland and Israel) demonstrate that for older European people the traditional scale is somewhat biased. The scale used and suggested by geriatricians for people aged 65 and more is also more appropriate for people aged 50-64. By this scale, the people having BMI 23.0-29.9 are taken as normal. This classification is, by SHARE data, consistent with people's self-esteem on their health, quality of life and coping with everyday life
\end{abstract}

Keywords: BMI, overweight, underweight, obesity, older people, elderly people, Europeans

\section{USING SHARE DATA FOR ASSESSING THE BODY MASS INDEX OF ELDERLY EUROPEANS}

\section{SHARE data}

Nowadays, statisticians can work with huge data sets. These are not only socalled big data that are, in general, collected without statistical aims and often have intractable structure, but the usual surveys are also rapidly growing in all dimensions. One of the big surveys we use in the paper is SHARE. SHARE is the acronym of the Survey on Health, Ageing and Retirement in Europe, which has been conducted in Europe since 2002 [http://www.share-project.org/]. Concerning this survey, it is important that, besides the usual person/variable 
dimensions, the time dimension also exists - the survey is repeated in every three years, and now the data of the fifth wave are available.

In Estonia, SHARE has been conducted twice - the fourth wave (2010) and the fifth wave (2013) [http://www.share-estonia.ee/]. The sixth wave is going to be finished in 2016. In this paper, only the data from the 5th wave are used. During this wave, about 65000 persons aged 50 years and more from 17 European countries (and Israel) were interviewed, see Figure 1.

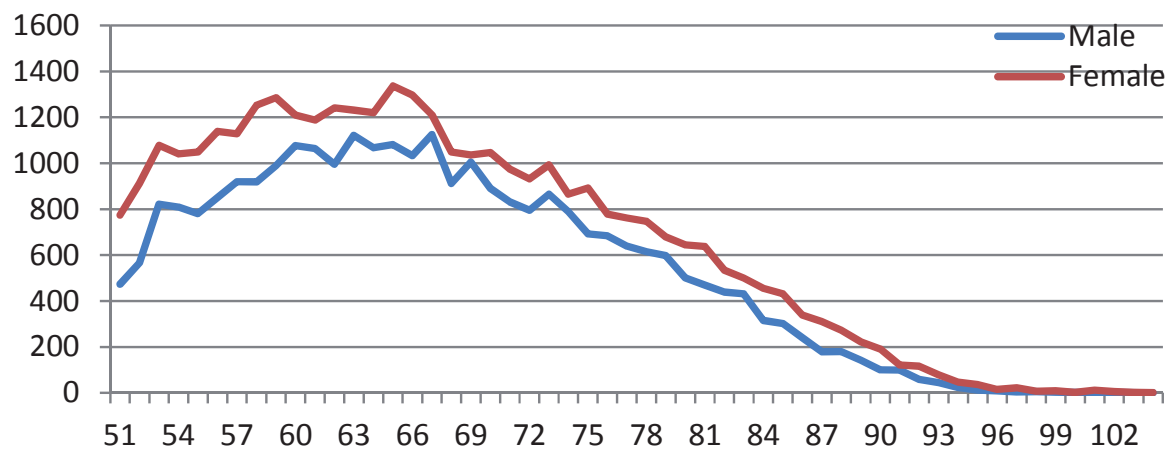

Figure 1. Age distribution of men and women interviewed in SHARE 5th wave.

Using weights, the survey allows us to draw conclusions on about 130 million people living in the area, see Figure 2.

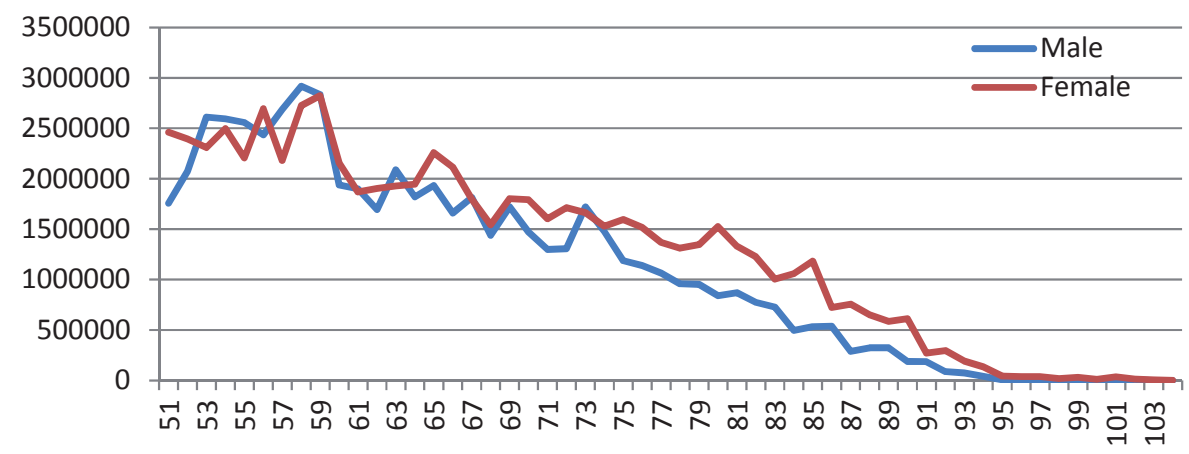

Figure 2. The size of sex-age cohorts (groups) described by SHARE data.

SHARE questionnaires are very long and exhaustive, concerning health problems, everyday life, the economic situation, etc., but also the body mass index (BMI). In addition, some objective tests like handgrip test and stand-up from a chair are done; in the last waves also some blood tests are included. 


\section{Quetelet index}

The Flemish statistician Adolphe Quetelet (1796-1874) [1] was the first scientist who started to use statistics in biosciences. Among other results he, elaborated in 1835 an indicator (BMI) to measure peoples' body structure (obesity index) using the following formula [2]:

$$
\mathrm{BMI}=\text { body mass }(\text { kilograms }) /[\text { height }(\text { meters })]^{2} \text {. }
$$

Quetelet advised to define as obese these people whose BMI is more than 30.

During the 180 years that have passed from the time when Quetelet worked, many different indicators for measuring people's body structure have elaborated (e.g. Ponderal index [3], body adiposity index [4], etc), but Quetelet's BMI is still the most popular, as its advantage is simplicity of measuring and calculation. That is the reason why the usage of BMI has dramatically increased nowadays; see Figure 1.

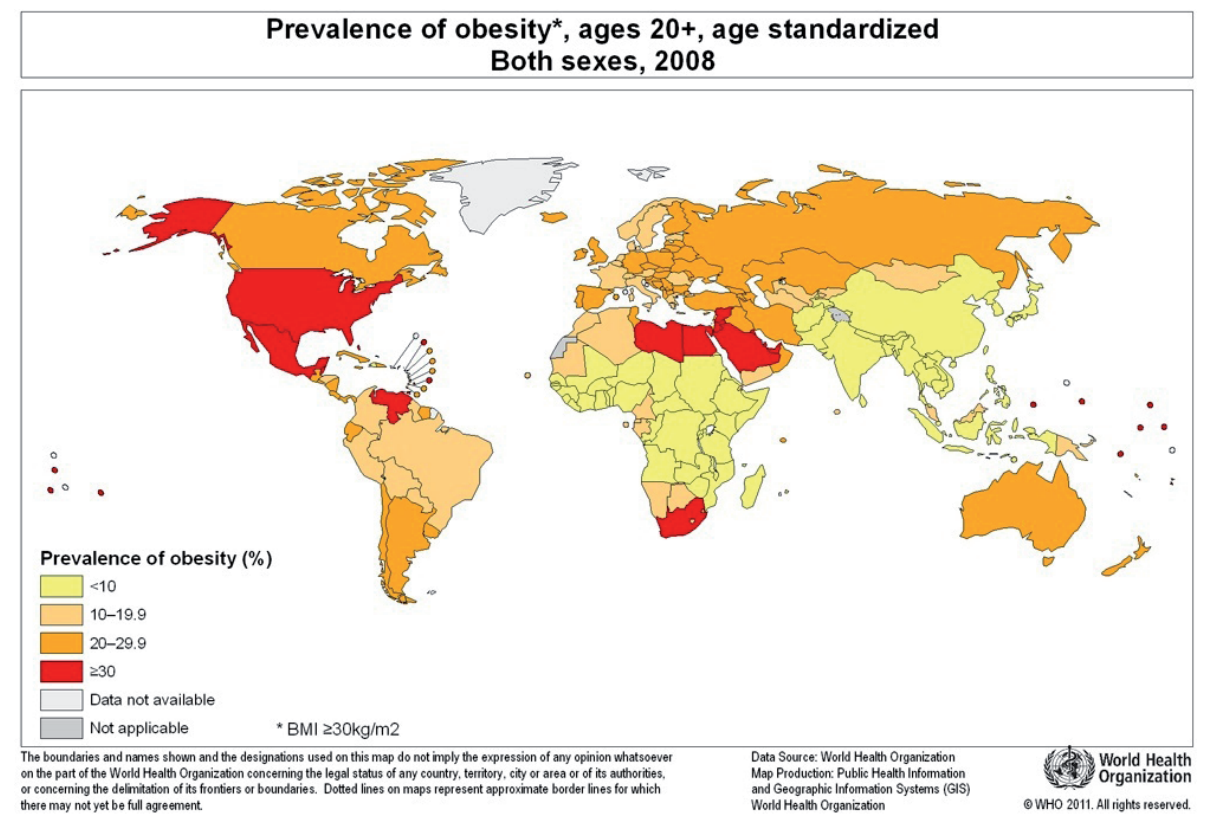

Figure 3. Obesity in global statistics [5].

During the last decade, obesity and overweight have become a serious problem in the world, and extensive research has been conducted on the topic. The main problem is the increase of overweight people in the world [see 5-7].

Among other indicators in SHARE, BMI was also calculated for almost 65000 persons. This material offers a good possibility to compare the BMIs 
of men and women aged 50 and more in different European countries and to check several common hypotheses about the influence of different factors on BMI and also BMI's impact on some indicators of quality of life.

\section{DEPENDENCE OF BMI ON AGE}

It is of interest to study how BMI changes when people have reached the age 50. Naturally, a more exact answer to the question can be received by analysing panel data, which means that the same person has to be measured repeatedly. Nevertheless, the existing data also give some picture on the distribution of BMI in different ages. In the following, the weighted population data are used. From Figure 4, it follows that people aged 59-70 have the highest average BMI. It is not clear if this is a common tendency or a specific feature of the given cohort, but in general, people of higher age $(70+)$ tend to have smaller values of BMI.

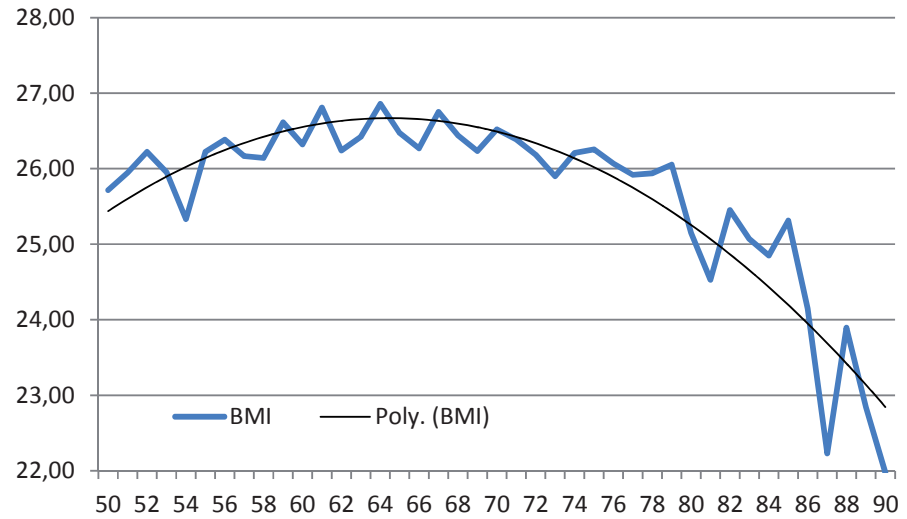

Figure 4. Change of BMI by age - its quadratic model (population data).

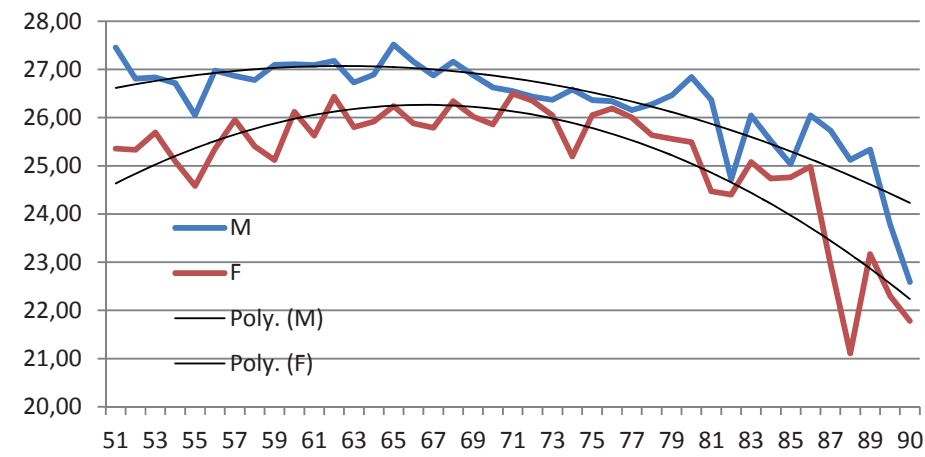

Figure 5. Change of BMI of men and women by age and quadratic models (population data). 
From Figure 5, it follows that, in general, the changes of BMI in men and women have the same tendency whereby in all ages men's BMI is somewhat higher than women's BMI. It is also visible that men reach the highest BMI values somewhat earlier than women - for men the highest average values (27+) occur in ages 59-68, for women the highest averages (26+) occur mainly in ages 68-77. This effect might be connected with men's shorter life expectancy, but there is no proof of this hypothesis.

\section{BMI of men and women aged 50+ in different countries}

In the following parts of the paper, we will use the common classification of people by usual classes of BMI.

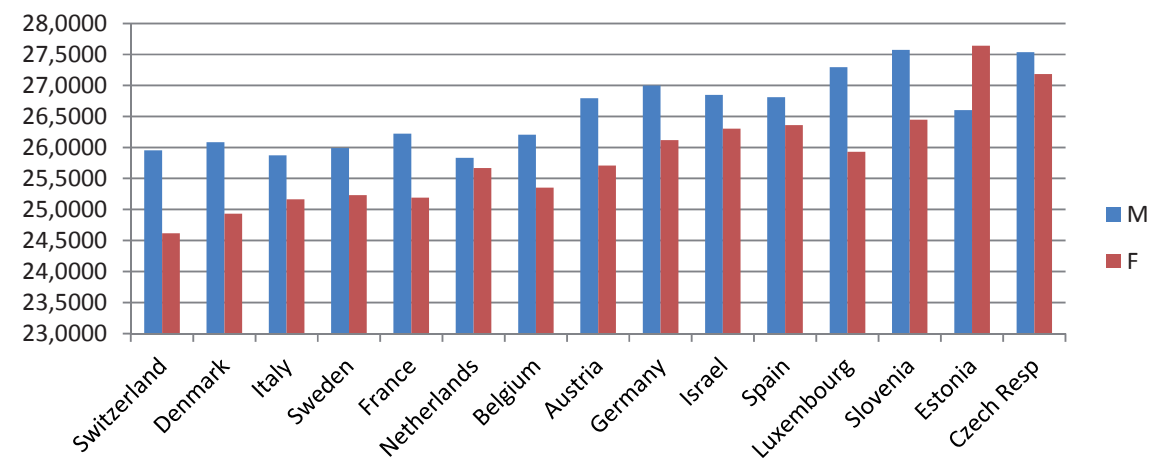

Figure 6. Average BMI in European countries (population data).

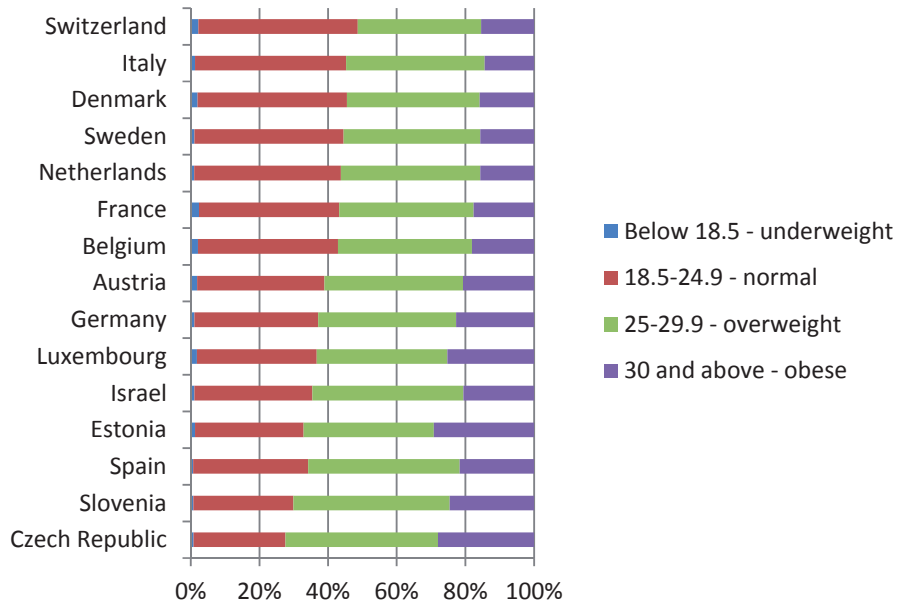

Figure 7. Distribution of body build groups defined by BMI in different countries. 
In Figure 6, the countries are sorted by the average BMI of all people measured. In most countries, BMI is higher in men than in women. Estonia is the only country where women's average BMI is higher than the same indicator of men. We can also see that Estonian women (aged 50+) have the highest value of BMI compared with the other countries studied. The second is the Czech Republic, followed by Slovenia.

Among men, the BMI value is the highest in Slovenia, the second is the Czech Republic (which has the highest total BMI among the countries studied). The following is Luxembourg. Estonian men are on 8th place, which is in the middle of the ranking. The smallest BMI is in Switzerland and in Denmark, which also have the smallest values for men and women accordingly.

Figure 7 shows that, according to common criteria of BMI, in all countries analysed, more than half of the population aged $50+$ are overweight or obese. The countries are ordered by the share of normal BMI that is highest (46\%) in Switzerland. Underweight of elderly people is not a problem in Europe - in general, the share of underweight people is $1.3 \%$ and reaches $2 \%$ only in a few countries. On the contrary, obesity of people aged $50+$ is a problem, as $18.7 \%$ of all people discussed belong to the class of obese people having BMI $>=30$. The problem of obesity is the most common in Estonia and the Czech Republic (28-29\% of age group); in Luxemburg and Slovenia also almost one quarter of the elderly population is obese. In total, the most common group is overweight (39.7\%) against normal (38.0\%).

\section{BMI classes of elderly people used by geriatricians}

For people aged 65 years and more, BMI 23.0-29.9 is considered normal by geriatricians. Consequently, people aged $65+$ and having BMI less than 23 , are underweight. The problem of losing weight in old age may have rather serious consequences (sarcopenia and frailty among others), so in general, for these people, malnutrition is a bigger clinical problem than overweight. Using this classification for elderly people surveyed by SHARE, we can see the following picture. 


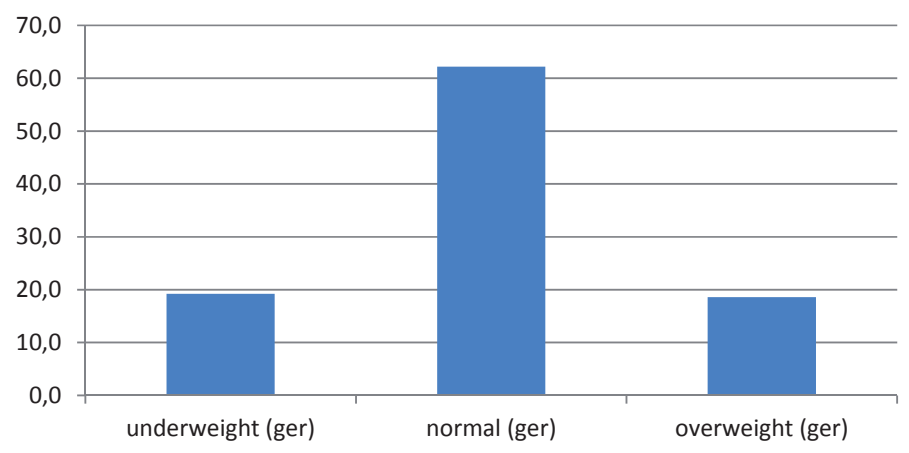

Figure 8. Classification of European elderly people by geriatricians' BMI classes.

The data show that, according to geriatric criteria of BMI, approximately one fifth of the elderly are either under - or overweight.

\section{FACTORS INFLUENCING BMI}

There are several factors that hypothetically influence BMI. Using SHARE data we can check some of them:

1. Women who have given birth to children have higher BMI;

2. Smokers have lower BMI;

3. BMI depends on eating regime, including regular eating of meat or regular eating of fruit/vegetables;

4. BMI depends on alcohol consumption.

Again, we did not have an exactly planned trial, and used the self-reported data, but it was still possible to make some conclusions using the rich database. As the amount of data was very big, we used sample data (without weighing) for checking the hypotheses.

\section{Influence of giving birth}

Information about this question was available only in the case of $70 \%$ women. ANOVA proved that having children influenced women's BMI $(\mathrm{p}<0.001)$, but most methods of multiple comparison (Tukey, Scheffe, Bonferroni) showed that the number of children did not have a significant influence on women's BMI. 


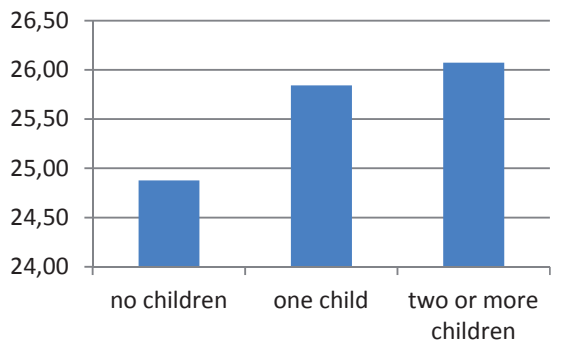

Figure 9. BMI of women depending on the number of children.

\section{Smoking and alcohol consumption}

Comparing the BMI value of people currently smoking $(\mathrm{BMI}=25.7)$ and nonsmokers $(B M I=26.5)$, the difference was significant $(\mathrm{p}<0.001)-$ as expected, the smokers had a lower body mass index.

According to their alcohol consumption, people can be divided into three groups: people consuming alcohol every week, people consuming alcohol every month or less and people who have not consumed alcohol during the last three months. BMI is highest in rare consumers and lowest in people consuming alcohol daily or several days a week. The differences between these groups are significant (by Tukey), but it is rather difficult to explain them.

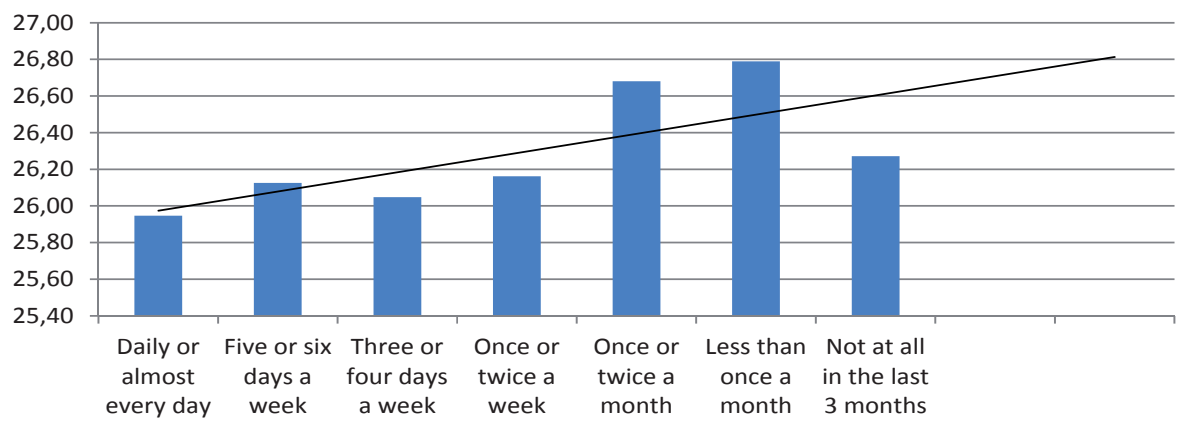

Figure 10. BMI depending on the frequency of alcohol consumption and its linear trend.

\section{Eating habits and BMI}

We asked two questions about eating habits. One concerns eating meat, fish or chicken and the second - eating vegetables and fruit. Both of them have a statistically significant impact on BMI $(\mathrm{p}<0.001)$, see Figures 11 and 12 . 
Figures 11 and 12 are seemingly quite similar but, in general, have a different direction, asserting that eating meat more often increases BMI and eating vegetables and fruit more often decreases the BMI, but the frequencies of the cases are quite different.

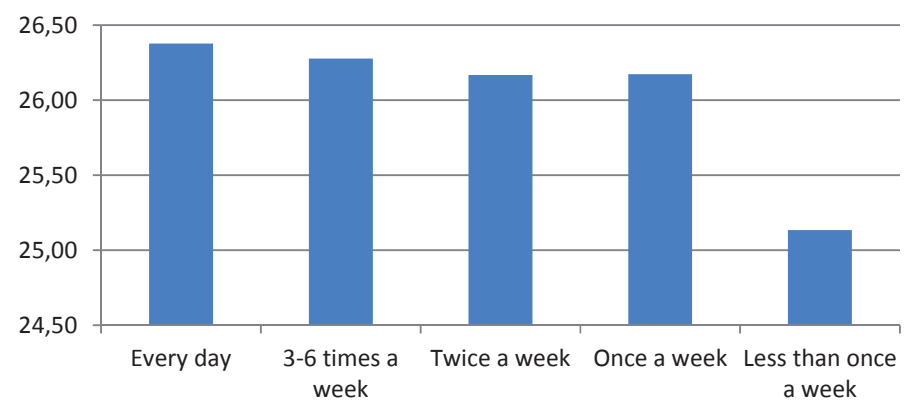

Figure 11. Frequency of eating meat, fish or chicken.

Eating meat every day is not very common in elderly Europeans - only less than $40 \%$ of people aged $50+$ do that; the most common case is eating meat 3-6 times a week. Eating vegetables and fruits was much more popular - almost $80 \%$ of population did this every day. Eating meat or eating vegetables less than once a week was quite exceptional; this happened in $1-2 \%$ of cases. This category of people differs significantly from all others $(p<0.001)$.

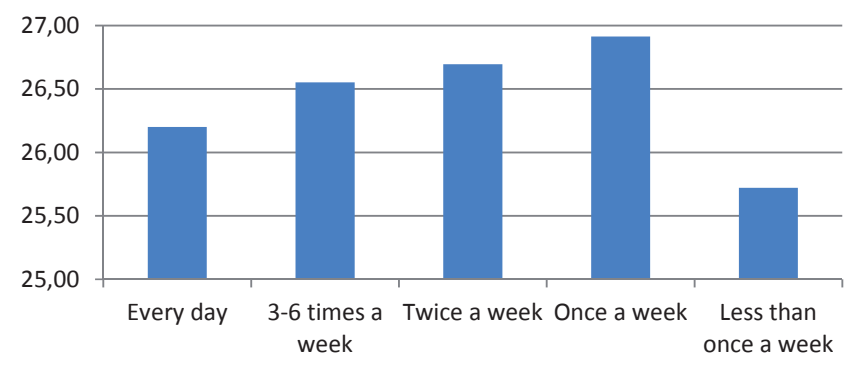

Figure 12. Frequency of eating vegetables and fruit.

The differences between BMIs of other groups were not all significant (by Tukey), but some interesting results still emerged. The BMI of people eating vegetables every day was significantly lower than the BMI of people eating vegetables not so frequently $(\mathrm{p}<0.001)$. 


\section{BMI and quality of life}

SHARE data measured several indicators that more or less conditionally demonstrate the quality of the respondent's life. One of them was self-assessment of general health, second - limitations in activities of every-day life caused by health conditions and the third was the CASP indicator of quality of life, which consisted of 4 components - control, autonomy, pleasure and self-realisation. All of these indicators were scaled so that the higher values showed the better quality of life: Health: 1 - poor, 2 - fair, 3 - good, 4 - very good, 5 excellent; limitations: 1 - severely limited, 2 - limited but not severely, 3 - not limited.

Figures 13-15 demonstrate the average values of these indicators depending on BMI values using the population (weighted) data. The values BMI $>40$ are not used, as they cover less than $1 \%$ of the population and, due to small groups, the dependency is not stable and smooth. The best approximations for these empirical dependence curves are cubic having average fitting rate $>0.8$ (by $\left.\mathrm{R}^{2}\right)$.

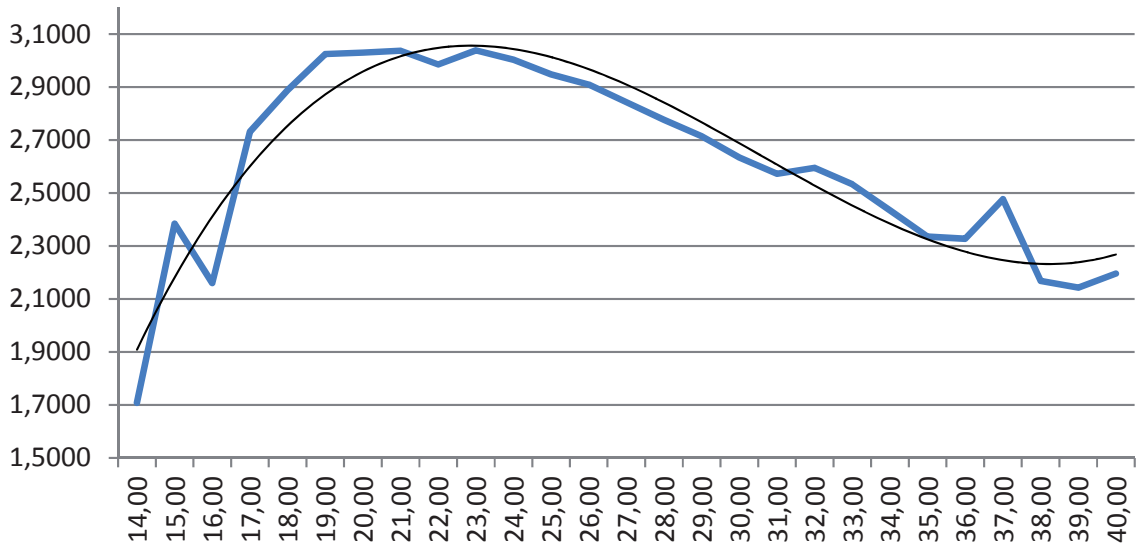

Figure 13. Mean value of estimated general health depending on BMI and its cubic approximation. 


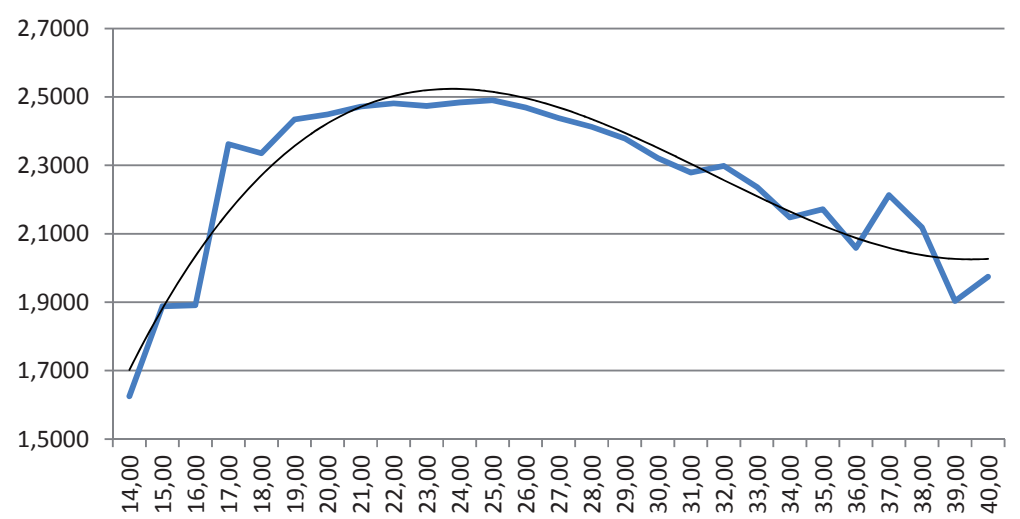

Figure 14. Mean value of estimated limitations depending on BMI and its cubic approximation.

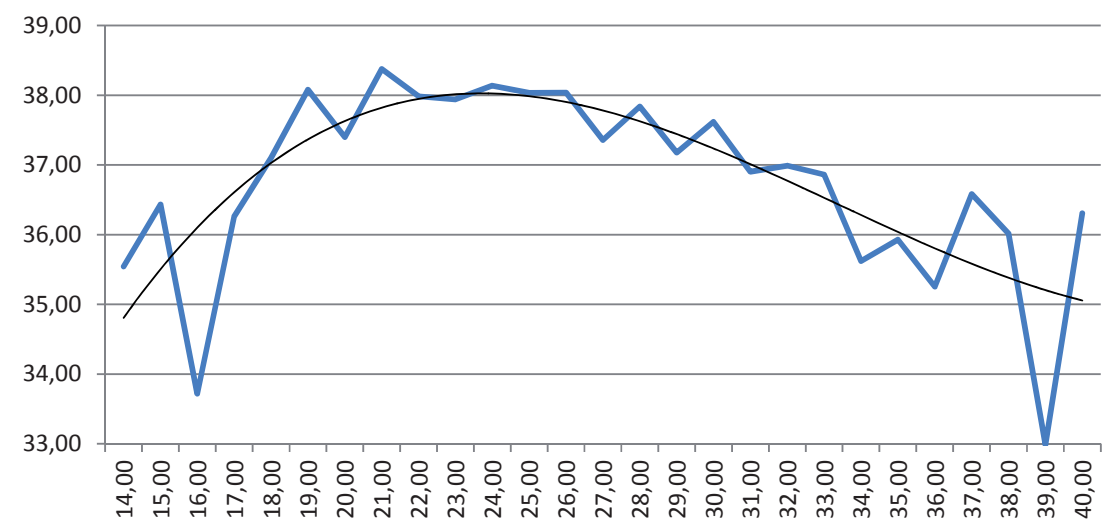

Figure 15. Mean value of the CASP index depending on BMI and its cubic approximation.

The cubic shape of the curve means that in the curve is not symmetric and decreases in small values of BMI more rapidly than in large values of BMI. In general, the optimal values of the indicator occurred when BMI value was 21-26, which covers $51 \%$ of the whole population, whereby part of them - 19\% of the population, are overweight.

\section{ESTONIANS' BMI COMPARED WITH OTHER EUROPEAN COUNTRIES}

\section{Distribution of BMI values in men and women}

When comparing the (weighted) distribution of BMI values in the European countries considered and in Estonia, we see that in the case of men the distri- 
butions are extremely similar: in both cases the distribution has a sharp peak (23-24\% of all cases) in values' interval 25-26 and is almost symmetric around this value.

Women's BMI distribution is more varied. It is less sharp in both cases and the maximal density is in the interval 25-26, but Estonian women often have higher BMI values than men, in other European countries the situation is opposite. Another small difference between Estonian and European distributions is that in Estonia the share of people having very low BMIs is smaller than in Europe in general.

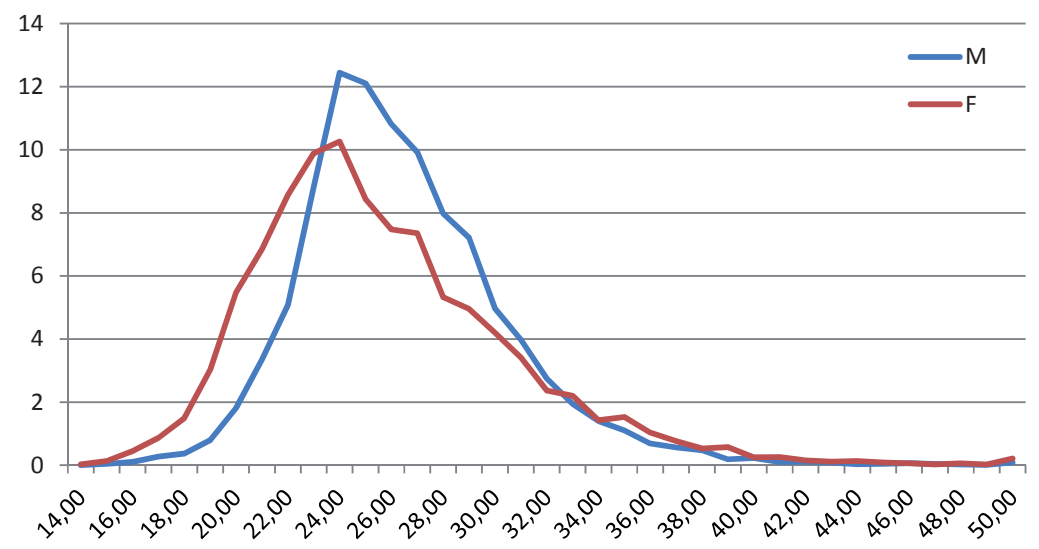

Figure 16. Distribution of BMI values in European countries (weighted).

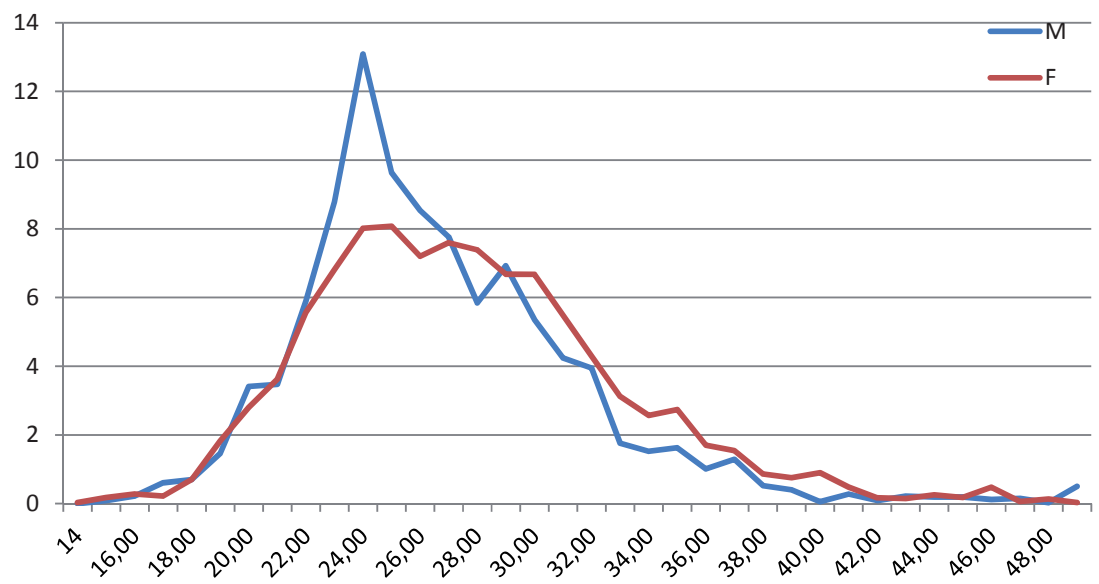

Figure 17. Distribution of BMI values in Estonia (weighted). 


\section{Do habits and having children influence BMI of Estonian people?}

All effects related to smoking, drinking and eating we detected the in European population were quite weak. We succeeded to detect them only due to the huge material - about 65000 persons were interviewed. As the Estonian sample in SHARE was only 5600, most of these effects were unnoticeable. Only the impact of smoking was proved (and more clearly than in the European countries on average): the BMI of smokers was 27.23, of non-smokers - 28.25.

The difference between childless women's BMI and BMI of women having at least one child was not significant in Estonia, but the difference between the BMIs of women having at least two children (28.31) and women having no children or one child (27.84) was significant $(\mathrm{p}=0.05)$.

\section{DISCUSSION}

It was ascertained that more than half (58.4\%) of the elderly people (aged $50+$ ) in Europe are overweight, if the traditional BMI scale is used.

The result is similar to earlier results carried out in several countries or for several age groups [5-7]. The tendency was common for all the countries considered - 16 European countries (15 from the EU and Switzerland) and Israel. The study covered (via weights) about 130 million people.

It is also remarkable that the factors related to everyday life and habits eating, drinking and smoking - had a very weak influence on BMI.

People whose BMI was 18-30, particularly 21-25, had a better quality of life. Connections with low quality of life were less evident in the case of obese people than those with malnutrition.

The results also refer to the question posed earlier for several times - are $\mathrm{BMI}$ as an indicator and its value 25 adequate for defining overweight? The facts that support this question are the following:

- People's body structure has changed during the 180 years that have elapsed from the time of Quetelet due to the changing environment and life-style, and therefore, it is questionable if the indicator of body structure reflects these changes.

- The value of BMI 25 taken as a threshold for overweight has no statistical or biological argumentation.

If an indicator shows that more than half of a population is not normal, maybe the indicator needs some rethinking. Maybe the threshold of BMI $=25$ between "normal" and "overweight" does not fit elderly Europeans in 21st century. In 
addition, studies have demonstrated that life expectancy of people aged 65 years and more, and even for the total adult population, is the longest for those whose BMI is $25-29[8,9]$.

Another option is to use the scale suggested by geriatricians. For the European people aged $65+$ the result is normal, see Figure 6 .

But still the problem remains for people aged 50-64, as the BMI distribution in Europeans aged 50-64 and 65+ is practically same, see Figure 18.

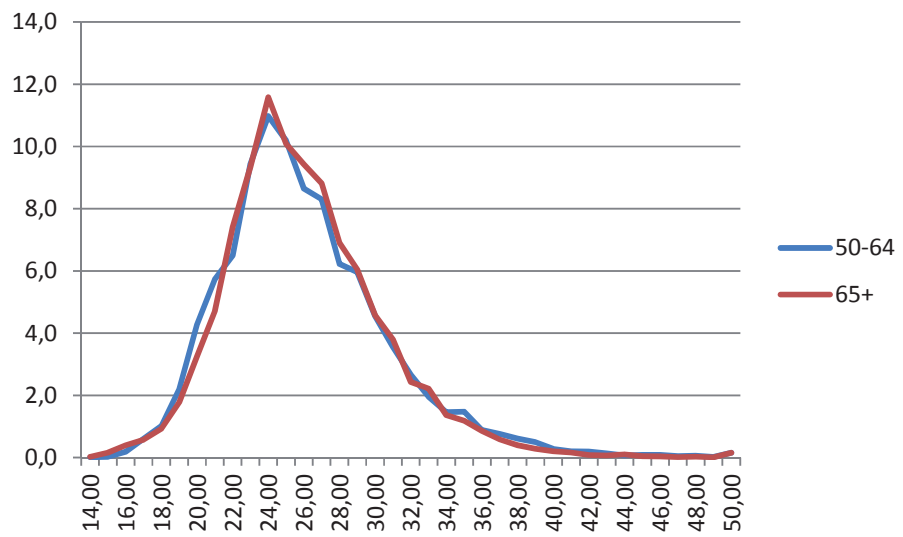

Figure 18. Distribution of BMI in European people aged 50-64 and 65+, population data (weighted).

The main conclusion we may draw from this study is:

The currently used "common" criteria for classifying people according to their BMI do not fit well for older European populations. Geriatric criteria might be more appropriate for people aged 50 years and more.

The research was partially supported by institutional research funding IUT34-5 of the Estonian Ministry of Education and Research.

\section{REFERENCES}

1. Adolphe Quetelet (1796-1874), http://mnstats.morris.umn.edu/introstat/history/w98/Quetelet.html

2. Body Mass Index, https://en.wikipedia.org/wiki/Body_mass_index

3. Ponderal index, https://en.wikipedia.org/wiki/Ponderal_index

4. Body adiposity index, https://en.wikipedia.org/wiki/Body_adiposity_index

5. Obesity in global statistics, http://www.bariatec.com/obesity-global-statistics/ 
6. Prevalence of Childhood and Adult Obesity in the United States, 2011-2012, Cynthia L. Ogden, Margaret D. Carroll, Brian K. Kit, Katherine M. Flegal, February 26, 2014, Vol 311, No. 8 > http://jama.jamanetwork.com/article. aspx?articleid $=1832542$

7. Overweight and obesity - BMI statistics, Eurostat, http://www.euro.who.int/en/health-topics/noncommunicable-diseases/obesity

8. Winter J.E., MacInnis M.J., Wattanapenpaiboon N., Nowson C.A. (2014) BMI and all-cause mortality in older adults: a meta-analysis. The American Journal of Clinical Nutrition. doi: 10.3945/ajcn.113.068122.

9. Steensma C., Loukine L., Orpana H., Lo E., Choi B., Waters C., Martel S. (2013) Comparing life expectancy and health-adjusted life expectancy by body mass index category in adult Canadians: a descriptive study. Population Health Metrics 11:21 http://www.pophealthmetrics.com/content/11/1/21

\section{Address for correspondence:}

Ene-Margit Tiit

Institute of Mathematical Statistics

Faculty of Mathematics and Computer Science

University of Tartu, Tartu, Estonia

J. Liivi 2-513, 50409 Tartu, Estonia

E-mail: ene.tiit@ut.ee 